\title{
Effect of massive bowel resection on enteroinsular axis
}

\author{
T. KAJIWARA, T. SUZUKI, AND T. TOBE \\ From the First Department of Surgery, Kyoto University Medical School, Kyoto, Japan
}

SUMMARY Pancreatic endocrine function was studied in 13 patients who had undergone massive bowel resection. The patients were divided into two groups: one month after operation (short-term group), and three or more months after operation (long-term group). Oral administration of glucose caused a persistent low insulin secretion in almost all the patients and the glucose tolerance curve showed a diabetic pattern in four. In contrast, the insulin response to intavenously infused arginine was impaired in the short-term group, but was at an approximately normal level in the long-term group. Pancreatic glucagon response to intravenous arginine, however, remained unchanged in both groups. Interruption of the enteroinsular axis as the result of massive bowel resection probably plays a major part in this discrepancy of the behaviour of insulin in the long-term group.

Oral administration of glucose produces a considerably greater rise in serum insulin levels than does intravenous administration of glucose (McIntyre et al., 1964). This evidence led Unger and Eisentraut (1969) to advocate the concept of an enteroinsular axis in which some hormones in the intestinal mucosa regulate the secretion of the islet cells. Several kinds of insulinotrophic agents which might be responsible for this phenomenon have been proposed on the basis of their distribution in the intestine. Massive bowel resection may induce interruption of the enteroinsular axis which follows the dysfunction of the islet cells.

There are few reports in the literature on changes in islet cell function after intestinal resection. The present study was an attempt to compare the endocrine function of the pancreas in patients with massive bowel resection with that of normal volunteers and to discuss the effect of intestinal resection on the enteroinsular axis.

\section{Methods}

CONTROLS

Ten healthy, normal volunteers (five females, five males) ranging in age from 32 to 65 years (mean 49.8 years) served as controls. All were within $10 \%$ of their ideal body weight.

PATIENTS With MASSIVE BOWEL RESECTION Thirteen patients (seven females, six males) ranging in age from 32 to 70 years (mean 53.6 years) were

Received for publication 22 March 1977 investigated. All had undergone surgery after the diagnoses listed in Table 1 . These patients were divided into the short-term and the long-term group according to the intervals after the operation. The former included six patients who had been operated on one month before and the latter included seven who had had surgery three or more months previously.

After an overnight fast, $50 \mathrm{~g}$ glucose was given orally and venous blood samples were collected to determine plasma glucose and insulin before and 30 , 60,90 , and 120 minutes after the oral glucose load. The insulinogenic index was determined by the ratio of increments of insulin over fasting levels at 30 minutes to those of blood glucose $(\triangle I R I / \triangle B S$ $(30 \mathrm{~min}))$. The output of insulin during the oral glucose tolerance test was calculated by measuring the area under each curve from fasting to 120 minutes $(\Sigma \triangle I R I(0->120 \mathrm{~min}))$ and expressed arbitrarily in $\mu \mathrm{U} / \mathrm{ml}$. On another day, L-arginine in a dose of $30 \mathrm{~g}$ was infused during a period of 45 minutes and blood samples were collected to determine plasma insulin and glucagon before, and six, 10, 20,30, 45, 60, and 90 minutes after the start of the infusion. The output of insulin and glucagon in response to arginine was also calculated by measuring the area under each curve from fastine to 90 minutes $(\Sigma \triangle$ IRI $(0->90 \mathrm{~min}), \Sigma \triangle \mathrm{IRG}$ $(0->90 \mathrm{~min}))$ and expressed arbitrarily as $\mu \mathrm{U} / \mathrm{ml}$ and $\mathrm{Pg} / \mathrm{ml}$ respectively. The insulin-glucagon ratio in the fasting state was computed (Unger, 1971). The blood glucose concentration was determined by using an autoanalyser. Plasma insulin level was determined radioimmunologically using a CIS-kit 806 
Table 1 Clinical features of patients with massive bowel resection

\begin{tabular}{|c|c|c|c|c|c|c|c|}
\hline Case no. & $\begin{array}{l}\text { Age } \\
(y r)\end{array}$ & Sex & $\begin{array}{l}\text { Body weight } \\
(\mathrm{kg})\end{array}$ & Diagnosis & $\begin{array}{l}\text { Part of small bowel } \\
\text { resected }\end{array}$ & $\begin{array}{l}\text { Length of small bowel } \\
\text { remaining } \\
(m)\end{array}$ & $\begin{array}{l}\text { Interval since } \\
\text { resection } \\
\text { (months) }\end{array}$ \\
\hline \multicolumn{8}{|c|}{ Short-term group } \\
\hline 1 & 41 & $\mathbf{f}$ & 45 & Adhesions ileus & Ileum & $2 \cdot 0$ & 1 \\
\hline 2 & 65 & $\mathrm{~m}$ & 51 & Incarceration & Ileum & $2 \cdot 2$ & 1 \\
\hline 3 & 52 & $\mathrm{f}$ & 47 & Adhesions ileus & Ileum & $2 \cdot 5$ & 1 \\
\hline 4 & 47 & f & 53 & Strangulations ileus & Jejunum & 1.8 & 1 \\
\hline 5 & 62 & $\mathrm{~m}$ & 67 & Intestinal rupture & $\begin{array}{c}\text { Jejunum } \\
\sim \text { ileum }\end{array}$ & 1.5 & 1 \\
\hline 6 & 58 & f & 44 & Adhesions ileus & Jejunum & 1.5 & 1 \\
\hline \multicolumn{8}{|c|}{ Long-term group } \\
\hline 7 & 38 & f & 53 & Adhesions ileus & Ileum & $2 \cdot 0$ & 3 \\
\hline 8 & 54 & $\mathrm{~m}$ & 72 & Intestinal rupture & $\begin{array}{c}\text { Jejunum } \\
\text { ileum }\end{array}$ & $1 \cdot 5$ & 12 \\
\hline 9 & 64 & $\mathbf{m}$ & 65 & Incarceration & Ileum & $2 \cdot 2$ & 4 \\
\hline 10 & 52 & f & 42 & Adhesions ileus & Jejunum & $2 \cdot 5$ & 5 \\
\hline 11 & 70 & $\mathrm{~m}$ & 55 & Adhesions ileus & Ileum & 1.5 & 156 \\
\hline 12 & 62 & m & 60 & Intestinal rupture & $\begin{array}{c}\text { Jejunum } \\
\text { ileum }\end{array}$ & 1.5 & 6 \\
\hline 13 & 32 & f & 50 & Intestinal rupture & Jejunum & $2 \cdot 0$ & 3 \\
\hline
\end{tabular}

and plasma glucagon with $30-\mathrm{K}$ antibody by the method of Unger and his colleagues (Unger et al., 1967). The glucose and arginine tests in the normal volunteers were repeated twice at several intervals, respectively, and the average of two readings was adopted.

\section{Results}

ORAL GLUCOSE TOLERANCE TEST

Table 2 summarises the results of the glucose tolerance test in the control, the short-term, and the long-term group. The fasting blood glucose remained at normal levels in all but one of the long-term group. After the glucose load, a diabetic curve (American Diabetes Association, 1969) was observed in two patients of both short-term and long-term groups. The remaining four of the short-term group and five

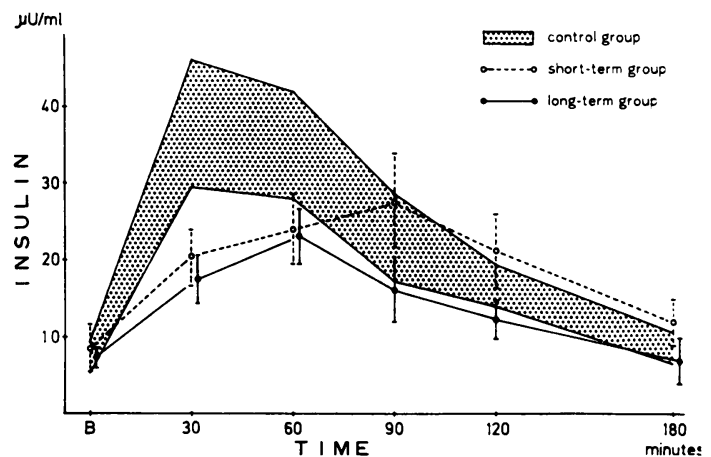

Fig. 1 Insulin secretion after oral glucose (mean $\pm S E)$.

of the long-term group were within normal limits. The secretion of insulin in this test was, as shown in Fig. 1, reduced both in the short-term and long-

Table 2 Plasma glucose levels in oral glucose and insulinogenic index (mean $\pm S E)$

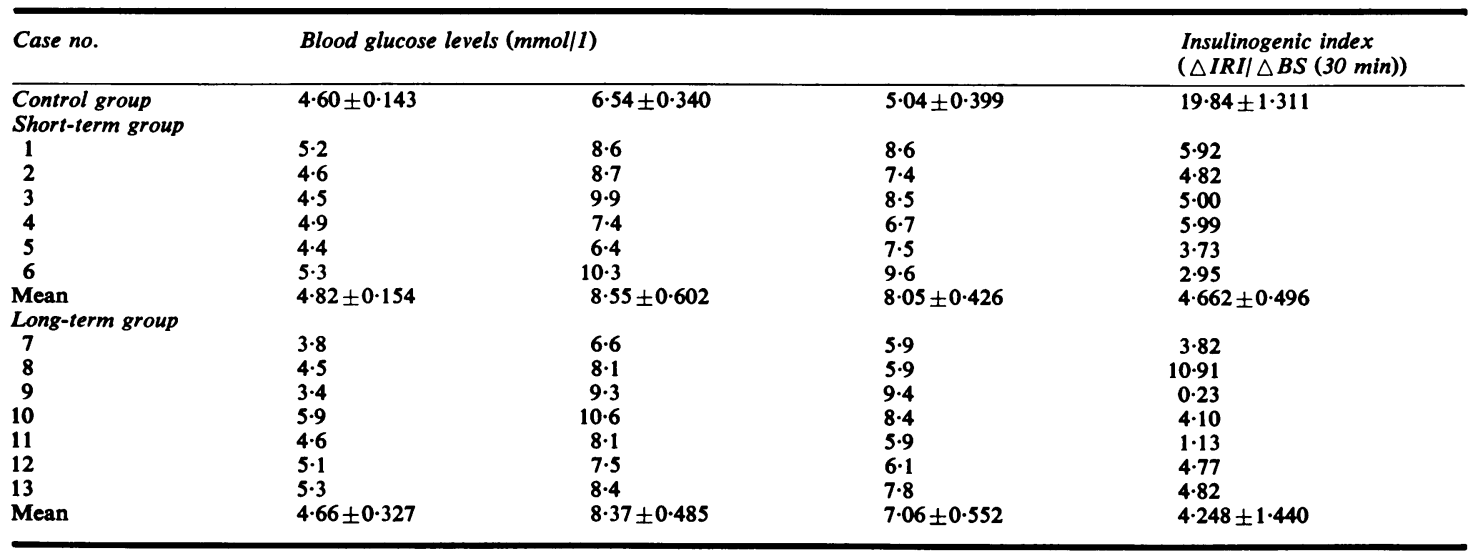




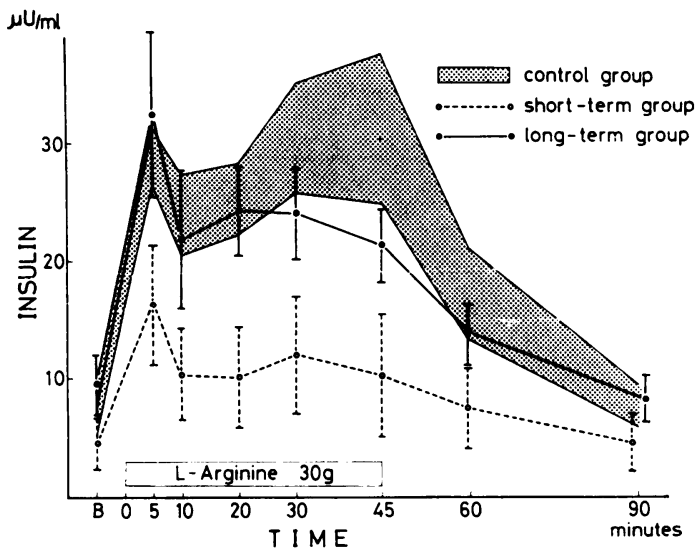

Fig. 2 Insulin response to intravenous arginine (mean $\pm S E$ ).

term group. The insulinogenic index in the control group was $19 \cdot 84 \pm 1 \cdot 311$, which decreased significantly to $4.662 \pm 0.496(\mathrm{P}<0.001)$ and $4.248 \pm 1.440$ $(P<0.001)$ in the short-term and the long-term group. The output of insulin during a 120 minute period after oral glucose load $(\Sigma \triangle \mathrm{IRI}(0->120 \mathrm{~min}))$ was $2599 \pm 211.8 \mu \mathrm{U} / \mathrm{ml}$ in the control group. It decreased to $1477 \pm 229.6 \mu \mathrm{U} / \mathrm{ml}(\mathrm{P}<0.005)$ in the short-term group and remained impaired $(1351 \pm 288.8 \mu \mathrm{U} / \mathrm{ml}$, $\mathbf{P}<0.005)$ even in the long-term group.

\section{INTRAVENOUS ARGININE LOAD}

\section{Insulin response}

As shown in Fig. 2, the insulin response to infused arginine was reduced in the short-term group but was almost to the level of the controls in the longterm group. The output of insulin in response to intravenous arginine $(\Sigma \triangle \mathrm{IRI}(0->90 \mathrm{~min}))$ in the control group was $1294 \pm 142 \cdot 5 \mu \mathrm{U} / \mathrm{ml}$, which de-

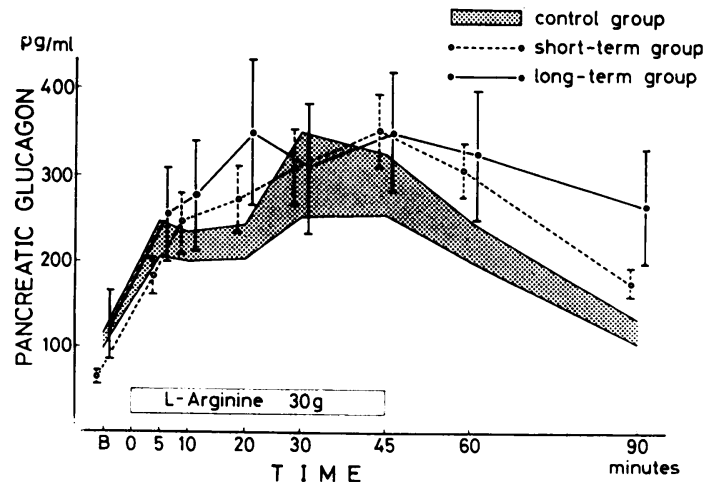

Fig. 3 Pancreatic glucagon response to intravenous arginine (mean $\pm S E$ ). creased to $421 \pm 157.0 \mu \mathrm{U} / \mathrm{ml}(\mathrm{P}<0.005)$ in the short-term group, but there was no statistical difference $(893 \pm 141.3 \mu \mathrm{U} / \mathrm{ml}, 0.1<\mathrm{P}<0.5)$ in the long-term group. Thus, insulin response to arginine was impaired significantly only in the short-term group.

PANCREATIC GLUCAGON RESPONSE

The response of glucagon to intravenous arginine was much the same as in the control group in both the short- and long-term groups (Fig. 3).

The output of glucagon in response to the stimulant $(\Sigma \triangle \mathrm{IRG}(0->90 \mathrm{~min})$ in the controls, the short-term group and the long-term group was $15471 \pm 1412 \cdot 2,18520 \pm 2488.9$ and $16549 \pm 6281 \cdot 8$ $\mathrm{pg} / \mathrm{ml}$, respectively. There were no statistical differences among these three groups.

Insulin glucagon ratio in the fasting state was $2 \cdot 148 \pm 0.446$ in the controls, but decreased significantly to $1.168 \pm 0.427(\mathrm{P}<0.05)$ in the short-term group. The ratio in the long-term group was $2 \cdot 060 \pm 0.550$, which was not statistically different from that in the controls.

\section{Discussion}

We found that plasma insulin response to oral glucose was impaired not only one month after but also more than three months after massive bowel resection. Similarly, insulin response to infused arginine was also reduced one month after the intestinal resection. The response at three months or more was much the same as in the controls. Malnutrition inevitably occurs after massive bowel resection, and is not compensated far until about one month after operation (Althausen et al., 1950). On the other hand, release of glucagon and insulin in response to infused arginine participates in glucose production and protein synthesis in the liver (Cherrington et al., 1974). Therefore, it is reasonable that the low insulin release mediated by arginine seen in the short-term group might be the result of post-operative catabolism and malabsorption of the protein. Unger (1971) also pointed out the low molar ratio of two pancreatic hormones in catabolic illness. In fact, the insulin glucagon ratio in our patients in the fasting state decreased only in the early stage after the operation.

The impaired glucose tolerance in two patients with massive bowel resection improved gradually with time. The blood glucose curve was quite normal by six months after the resection. These occurrences are the result of enhanced glucose absorption by the intestinal remnants (Dowling and Booth, 1966; Weinstein et al., 1969). In the present study, glucose tolerance was disturbed in only four of 13 patients 
with massive intestinal resection, while the insulinogenic index in oral glucose load was impaired in almost all the patients, including one who had undergone surgery 10 years before. Thus, the low insulin serection in response to oral glucose is probably the result of impairment of insulin release from islet cells rather than of a disturbance in glucose absorption.

Wapnick and Jones (1972) reported that glucose tolerance after intestinal resection showed a marked decrease in insulin response to intravenously administered glucose, but not to oral glucose. They attributed this finding to a decrease in the fasting release of the alimentary insulinotrophic agents, including gastrin, secretin, pancreozymincholecystokinin, and enteroglucagon. The discrepancy between these results and our present data may be due to the area and/or length of the small intestine which had been resected. As is well known, glucose and amino acids give rise to a greater release of insulin, when they are administrated via the gastrointestinal tract than via the intravenous route (McIntyre et al., 1964). Based on this evidence, the concept of an enteroinsular axis was proposed (Unger and Eisentraut, 1969) and the importance of enteric factors which regulate islet cell function was stressed. Our findings that insulin response to oral glucose remained suppressed even for a long time after resection, while the response to intravenously administered arginine returned to the control levels may be explained by the interruption of the enteroinsular axis as the result of resection of the small intestine.

In fact, arginine is considered to have a different mechanism of action compared with glucose. But even the mechanism of insulin release from $\beta$ cell in response to intravenously administered glucose is not quite the same as in response to oral glucose. Our objective in this paper was to compare the behaviour of insulin via the enteroinsular axis with that of insulin via the non-enteroinsular axis. The chief reason for using arginine was to determine how pancreatic glucagon acts in the short bowel syndrome.

In contrast with the obvious impairment of insulin release, normal secretion of pancreatic glucagon in arginine infusion was observed after intestinal resection. As presented in the bihormonal disorder hypothesis, there is an absolute or relative hypersecretion of glucagon in addition to an absolute or relative insulin deficiency in diabetes mellitus (Unger, 1971). In our results, hypersecretion of glucagon relative to insulin in response to intravenous arginine was found in the short-term group, but not in the long-term group. The lowered insulin release to arginins in the early postoperative period can be explained by catabolism after operation: this relative hyperglucagonemia to arginine is manifested in the postoperative catabolic state. Meanwhile, low insulin secretion in response to oral glucose was observed in both short- and long-term groups. Accordingly, it can be stated that relative hypersecretion of glucagon remains after intestinal resection, when insulin glucagon ratio is calculated against the ratio of insulin in glucose to glucagon in arginine. This diabetic state induced by a relative hyperglucagonemia may be the result of loss of the intestinal 'signal' in the mechanism of insulin release in $\beta$ cells.

Reduction or loss of certain insulinotropic hormones is responsible for the lowered insulin secretion after bowel resection. According to recent literature, secretin (Unger et al., 1967; Kraegen et al., 1970), pancreozymin-cholecystokinin (Unger et al., 1967), enteroglucagon (Unger et al., 1968), gastrin (Unger et al., 1967), gastric inhibitory polypeptide (Dupre et al., 1973) are all regarded as insulinotrophic hormones in the gastrointestinal tract. Among them, release of a gastric inhibitory polypeptide has been described after oral ingestion of glucose (Brown et al., 1975). This hormone is apparently located throughout the small intestine in man (Thomas et al., 1977). Recently, the lower response of gastric inhibitory polypeptide to a test meal was found in patients with coeliac disease (Creutzfeldt et al., 1976), and this has been attributed to the numerical reduction of GIP cells in the small intestine in coeliac disease. It may be that after intestinal resection the absolute number of GIP cells decreases in the short bowel syndrome and that the lack of stimulation by this hormone results in a low insulin release.

Another factor responsible for the impaired insulin secretion after bowel resection may be enteroglucagon. Enteroglucagon is found throughout the small intestine, particularly in the lower area (Bloom, 1974) and is released after glucose ingestion (Unger et al., 1968). The secretion of enteroglucagon was found to be suppressed after massive intestinal resection in dogs (Barros D'Sa and Buchanan, 1977).

A decrease in the number of intestinal endocrine cells may result in an interruption of the enteroinsular axis, which results in a low insulin secretion in short bowel syndrome.

We are grateful to M. Ohara, Kyoto University, for assistance with the manuscript.

\section{References}

American Diabetes Association, Committee on Statistics (1969). Standardization of the rral glucose tolerance test. Report, Diabetes, 18, 299-310. 
Althausen, T. L., Doig, R. K., Uyeyama, K., and Weiden, S. (1950). Digestion and absorption after massive resection of the small intestine. 2. Recovery of the absorptive function as shown by intestinal absorption tests in two patients and a consideration of compensatory mechanisms. Gastroenterology, 16, 126-139.

Barros D' Sa, A. A. B., and Buchanan, K. D. (1977). Role of gastrointestinal hormones in the response to massive resection of the small bowel. Gut, 18. 877-881.

Bloom, S. R. (1974). Hormones of the gastrointestinal tract. British Medical Bulletin, 30, 62-67.

Brown, J. C., Dryburgh, J. R., Ross, S. A., and Dupré, J. (1975). Identifications and actions of gastic inhibitory polypeptide. Recent Progress in Hormone Research, 31, 487-532.

Cherrington, A. D., Kawamori, R., and Vranic, M. (1974). Arginine infusion in dogs. Model for the roles of insulin and glucagon in regulating glucose turnover and free fatty acid levels. Diabetes, 23, 805-815.

Creutzfeldt, W., Ebert, R., Arnold, R., Frerichs, H., and Brown, J. C. (1976). Gastric inhibitory polypeptide (GIP), gastrin and insulin: response to test meal in coeliac disease and after duodeno-pancreatectomy. Diabetologia, 12, 279-286.

Dowling, R. H., and Booth, C. C. (1966). Functional compensation after small-bowel resection in man. Demonstration by direct measurement (Letter). Lancet, 2, 146-147.

Dupre, J., Ross, S. A., Watson, D., and Brown, J. C. (1973). Stimulation of insulin secretion by gastric inhibitory polypeptide in man. Journal of Clinical Endocrinology and Metabolism, 37, 826-828.
Kraegen, E. W., Chisholm, D. J., Young, J. D., and Lazarus, L. (1970). The gastrointestinal stimulus to insulin release. II. A dual action of secretin. Journal of Clinical Investigation, 49, 524-529.

McIntyre, N., Holdsworth, C. D., and Turner, D. S. (1964). New interpretation of oral glucose tolerance (Letter). Lancet, 2, 20.

Thomas, F. B., Shook, D. F., O'Dorisio, T. M., Cataland, S., Mekhjian, H. S. Caldwell, J. H., and Mazzaferri, E. L. (1977). Localization of gastric inhibitory polypeptide release by intestinal glucose perfusion in man. Gastroenterology, 72, 49-54.

Unger, R. H., (1971). Glucagon and the insulin: glucagon ratio in diabetes and other catabolic illness. Diabetes, 20, 834-838.

Unger, R. H., and Eisentraut, A. M. (1969). Entero-insular axis. Archives of Internal Medicine, 123, 261-266.

Unger, R. H., Ketterer, H., Dupré, J., and Eisentraut, A. M. (1967). The effects of secretin, pancreozymin, and gastrin on insulin and glucagon secretion in anesthetized dogs. Journal of Clinical Investigation, 46, 630-645.

Unger, R. H., Ohneda, A., Valverde, I., Eisentraut, A. M., and Exton, J. (1968). Characterization of the responses of circulating glucagon-like immunoreactivity to intraduodenal and intravenous administration of glucose. Journal of Clinical Investigation, 47, 48-65.

Wapnick, S., and Jones, J. J. (1972). Changes in glucose tolerance and serum insulin following partial gastrectomy and intestinal resection. Gut, 13, 871-873.

Weinstein, L. D., Shoemaker, C. P., Hersh, T., and Wright, H. K. (1969). Enhanced intestinal absorption after small bowel resection in man. Archives of Surgery, 99, 560-562. 